\title{
Service Gap Analysis of Indian Railways in Trivandrum and Ernakulam Districts
}

\author{
R. P. C. S. Rajaram \\ Research Centre for Consumerism, Kalasalingam University, Sivakasi, Tamilnadu, India \\ pcsrajaram@yahoo.co.in
}

\begin{abstract}
Indian Railways is the largest rail network in Asia and world's second largest under a single management. This study aims to identify the perception and expectation level of the passengers towards the service provider in Trivandrum and Ernakulum districts and to identify relative importance of service quality dimensions rated by the passengers. Descriptive research was adopted and the Multistage Area sampling was constructed by taking a series of simple random samples in various stages. A structured questionnaire developed by the researcher and primary data is collected through interview scheduling method. The overall opinion towards service provider in Ernakulum and Trivandrum districts are satisfied by the passengers. By applying the gap analysis, it shows that lowest service gap is occurred in "assurance" and "reliability" dimension and little bigger service gap is occurred in the "tangibility" dimension. The empirical investigation study is able to accomplish research objectives, by thoroughly analyzed and identified competitive position of railways strengths and weaknesses among the passengers.
\end{abstract}

Keywords: Service Quality Dimensions, Service Gap, Descriptive Research, Multistage sampling

\section{Introduction}

Railway is being more energy efficient mode of transport, which are ideally suited for movement of bulk commodities and for long distance travel. Indian Railways is the largest rail network in Asia and world's second largest under a single management. It is the second largest employer in the world after the China Military.It runs 11,000 trains everyday, including 7,000 passenger trains. The passenger traffic has increased from 1.28 to 4.2 billion in the last 40 years, making Indian railways (IR) a leading passenger carrying railway in the world. For an administration purpose, the Indian Railways is divided into seventeen zones. The Indian Railways has realized that the mantra for making profit is customer satisfaction through higher service quality. Indian railways considered the fact that they have clearly understood the need of their customers like reduction in fares and travel time, introduction of new trains, garage conversion, provision of basic amenities, special up gradation schemes, on-line booking, etc. All 'A' and 'B' category stations will to be made as model stations. Modern facilities such as ATMs, cyber cafe, upgrade retiring rooms, waiting rooms, station buildings; lavatories etc. are to be provided at major stations. The i-ticket and c-ticket will also be brought through Rail Travel Service Agents and 800 more UTS centers to be opened.

Southern Railway, in its present form, came into existence on $14^{\text {th }}$ April 1951 through the merger of three state railways namely Chennai and Southern Mahratta Railway and Mysore state railway. Southern Railway (SR) is credited to be the first railway zone that sought establishment in liberated India. The capital city of Tamil Nadu, Chennai serves as the headquarters of Southern Railway. The zone has been segregated into six divisions namely Chennai, Madurai, Salem, Palakkad, Thiruvananthapuram (Trivandrum) and Tiruchirapalli. This study reveals the measurement of service quality and service gap analysis in Kerala railways with special reference to Trivandrum and Ernakulam districts. The study seeks to achieve the following objectives;

- To identify the perception and expectation level of the passengers towards the service provider in Trivandrum and Ernakulum districts.

- To identify relative importance of service quality dimensions rated by the passengers

- To determine overall satisfaction of the passengers towards the service provider

- $\quad$ To suggest the ways to improve service quality offered by service provider

\section{Review of Literature}

Many studies have been conducted on the customer satisfaction. An attempt has been made to present in brief, a review of literature on customer satisfaction in general as well as on the customer satisfaction 
from railway services. Parasuraman et al. (1985) formulated a measure for service quality derived from data on a number of services, instead of counting on earlier dimensions of 'goods quality' in the manufacturing sector. The initial results, based on some focus group findings, yielded 10 dimensions of service quality that included tangibles, reliability, responsiveness, competence, courtesy, creditability, security, access, communication and understanding the customer. Further empirical scrutiny resulted in a 22 item scale, called 'SERVQUAL', which measures service quality based on five dimensions namely tangibles, reliability, responsiveness, assurance and empathy. Rust \& Oliver (1994) further defined satisfaction as the "customers' fulfillment response", which is an evaluation as well as an emotion-based response to a service. They also assessed service satisfaction using items that include interest, enjoyment, surprise, wise choice and doing the right things.

Vanniarajan \& Stephen (2008) identified the linkage between RAILQUAL and passengers' satisfaction is also evaluated by the data collected from the passengers of Southern Railways. The important RAILQUAL factors identified by the passengers are reliability, assurance and empathy. The service offered by southern railways is up to the expectation of their passengers. The significantly and positively influencing RAILQUAL factors on the passenger's satisfaction and image of the Indian railways are its reliability and empathy. The intangible aspects of service performance of Indian railways have a strong direct and positive effect on the passenger's favourable attitude and image. This study would help the policymakers to monitor, control and improve their service at the international level. It can also be used as an evaluation tool for comparing the performance of Indian railways with reference to the passengers' expectation. Geetika \& Nandan (2010) viewed that service quality as a determinant of customer satisfaction. Different dimensions of service quality have been considered by various researchers. This study identifies components of service quality of Indian Railways at railway platforms. The study is exploratory in nature and uses factor analysis to identify the most important factors of customer satisfaction with service quality. The research methodology is empirical, and a survey of passengers (customers) was conducted. The findings reveal that five factors are considered important for determining satisfaction with railway platforms, the most important of which are refreshments and behavioral factors. Managerial and theoretical implications are drawn and discussed in the paper, and a model is proposed.

Rahaman \& Rahaman (2010) focused on the railway transportation sector and to develop a model defining the relationship between overall satisfaction and service quality attributes in a selective route from Khulna to Rajshahi in southwestern zone of Bangladesh so that it can reinforce further improvement process. Findings show that, overall service satisfaction depend on eight distinct service quality attributes. It implies the service with worst situation, overall satisfaction of service and need for priority improvement to support further orientation, addition and betterment of service to draw maximum economic and development benefit for those linking regions. Maruvada \& Bellamkonda (2010) identified that attributes to evaluate the quality of Railway Passenger Services and develops a comprehensive instrument "RAILQUAL" on the basis of SERVQUAL and Rail Transport quality. Fuzzy set Theory has been applied to evaluate the service quality of the Indian Railways. This paper develops an analysis architecture, which consists of fuzzy measurement of S-I (Satisfaction-Importance) degree. The measurement of S-I gap with fuzzy approach is to reduce subjectivity and ambiguity of passengers' judgment of service quality. Fuzzy logic helps in representing the vagueness of evaluators' judgment. Using SERVQAUL methodology, the optimal fuzzy interval of gap scores is determined for each item. Fuzzy approach is a more realistic way to use linguistic assessments instead of numerical values. An empirical study is conducted using the proposed approach. The following hypotheses are derived from theoretical underpinning.

- $\mathrm{H}_{1}$ : There is evidence to indicate that customer's perception will be lower than expectation of the service offered by railways sector

- $\mathrm{H}_{2}$ : There is an absence of significant evidence that Overall Satisfaction will have a significant impact on individual service quality dimensions of Railways.

\section{Research Methodology}

The descriptive research was applied in the research methodology of project work. The main characteristic of this method is that researcher has no control over the variables and he/she can report what has happened or what is happening. Multistage Area sampling was constructed by taking a series of 
simple random samples in various stages. This type of sampling is often more practical than simple random sampling for studies requiring "on location" analysis. Sample size selected for the study is 150. A structured questionnaire was developed by the researcher and primary data is collected through interview scheduling method. Statistical tools applied for data analysis are exploratory factor analysis, reliability analysis, multiple regression, ranking method and descriptive statistics.

Questionnaire Construction: The first part of questionnaire contains basic demographic variables of the passengers. In the second part, customers are asked to rate the overall satisfaction and overall service quality of the railways in seven-point scale. In the third part, passengers are asked to rank the factors that influence them to choose service provider (railways). In the fourth part, the customers are asked to rate the perception and expectation level towards service provider by assigning 26 statements into a preset of five service quality dimensions like reliability, assurance, empathy, tangibility and responsiveness. Hence a pool of 26 statements is finalized for inclusion in the final scale. The scale items are measured on a seven-point scale ranging from "extremely good" $(=7)$ to "extremely poor" $(=1)$. The questionnaire is constructed with the support of expert opinion (railway station master), executives, doctoral fellows in the area of services marketing and customer opinion. The scale has laid a strong foundation for evolving items in SQ (Service Quality) measurement taken for the present study. Totally twenty six statements related to service quality of railways are developed and purified through substantiation of the literature.

Reliability of RAILQUAL Instrument: The final stage of scale development process is assessment of reliability and validity of proposed scale. The Cronbach alpha coefficients of RAILQUAL dimensions, after the purification process, are briefly explained in the following table 1 and 2 .

Table 1 represents the individual item of RAILQUAL Cronbach value. The five $S Q$ dimensions for total scale have resulted in good internal consistency, which is evidenced by Alpha method. All the five SQ dimensions of RAILQUAL instrument have a coefficient alpha value of 0.934 in perception scale and 0.951 in expectation scale. Table 2 presents mean for twenty six items of RAILQUAL instrument, consisting of seven point scale. As can be seen in the reliability item statistics, all the 26 items seems to be reasonably well to the scale's reliability. A deletion of any item doesn't reflect much on the Cronbach's alpha value (see table 1). Another method to decide the reliability of the RAILQUAL scale of railways is to analyze the inter-item correlations. As per thumbs' rule, the Inter- item correlation should exceed 0.30 and the Cronbach alpha value should exceed 0.70 for the data to be reliable. The item statistics presents the current study statistics where Inter-item correlation is 0.367 for perception scale and 0.450 for expectation scale.

Validity test of RAILQUAL instrument: The next stage of data analysis is to explore dimensions of Service Quality in the railways. The explorative factor analysis should be analyzed in order to reach underlying factors that have the most effect in customer expectation. By applying explorative factor analysis, results are subjected to varimax rotation with Kaiser Normalization.

The appropriateness of using factor analysis depends on number of KMO. The table 3 shows the KMO (Kaiser-Meyer-Olkin) value appropriateness of factor analysis (0.903). Sampling adequacy for proceeding the explorative factor analysis is satisfactory and all 26 items are significant $(\mathrm{p}<0.05)$. As per condition, KMO value should be bigger than 0.70 . Result of Bartlett's test of Sphericity has taken for this study is equal to significant 0.000 which confirms our method. Principle component analysis is applied, out of 26 items, five components are extracted. The five extracted components are a) Staffs of the railway service sector have the ability in solving the problem of passengers, 0.770 factor loadings b) Performance of service correctly, 0.776 factor loadings c) Timely provision of service 0.732 factor loadings d) Accuracy in record keeping, 0.589 factor loadings e) Accuracy in timing of trains, 0.715 factor loadings 
Table 1: Estimation of the Cronbach's alpha value for RAILQUAL instrument

\begin{tabular}{lccc}
\hline \multicolumn{1}{c}{ Perception Scale } & & \multicolumn{2}{c}{ Expectation Scale } \\
\hline \multicolumn{1}{c}{ RAILQUAL items } & $\begin{array}{c}\text { Cronbach's } \\
\text { Alpha }\end{array}$ & $\begin{array}{c}\text { RAILQUAL } \\
\text { items }\end{array}$ & $\begin{array}{c}\text { Cronbach's } \\
\text { Alpha }\end{array}$ \\
\hline Staffs of the railway service sector have the ability in & 0.931 & E1 & 0.952 \\
solving the problem of passengers & & & \\
Performance of service correctly & 0.930 & E2 & 0.951 \\
Timely provision of service & 0.930 & E3 & 0.950 \\
Accuracy in record keeping & 0.932 & E4 & 0.949 \\
Accuracy in timing of trains & 0.931 & E5 & 0.949 \\
Clarity of announcements & 0.932 & E6 & 0.948 \\
Reliability Cronbach's Alpha mean & 0.934 & & 0.951 \\
Courtesy shown by staff & 0.930 & E7 & 0.948 \\
Ease of communication with the staffs of railways & 0.930 & E8 & 0.948 \\
Making customers feel safe during their travel stations & 0.931 & E9 & 0.949 \\
Trust towards the staff & 0.930 & E10 & 0.948 \\
Knowledgeable staffs in answering the passengers & 0.931 & E11 & 0.949 \\
Assurance Cronbach's Alpha mean & 0.934 & & 0.951 \\
Special care in dealing with passengers & 0.929 & E12 & 0.947 \\
Favorable attitude towards passengers & 0.929 & E13 & 0.948 \\
Having the customers best interest at heart & 0.929 & E14 & 0.947 \\
Convenient business hour & 0.930 & E15 & 0.948 \\
Paying individual attention to all types of passengers & 0.930 & E16 & 0.948 \\
Understanding the needs of the customer & 0.930 & E17 & 0.948 \\
Empathy Cronbach's Alpha mean & 0.934 & & 0.951 \\
Infrastructure facilities at stations & 0.931 & E18 & 0.948 \\
Infrastructure facilities at Trains & 0.930 & E19 & 0.948 \\
Availability of equipments at stations & 0.930 & E20 & 0.947 \\
Appearance of staff & 0.931 & E21 & 0.947 \\
Tangibility Cronbach's Alpha mean & 0.934 & & 0.951 \\
Promptness in satisfying the requests & 0.930 & & 0.947 \\
Staffs sincerity in service & 0.931 & E23 & 0.948 \\
Prompt service to passengers & 0.930 & E24 & 0.948 \\
Willingness to help the passengers & 0.930 & E25 & 0.948 \\
Availability of staffs to respond the passengers & 0.930 & E26 & 0.948 \\
Responsiveness Cronbach's Alpha mean & 0.934 & & 0.951 \\
\hline
\end{tabular}

Table 2: Reliability item statistics for RAILQUAL

\begin{tabular}{lcc}
\hline & Perception Scale & Expectation Scale \\
\hline Item Means & 4.531 & 6.368 \\
Item Variances & 2.198 & 0.816 \\
Inter-Item Covariance's & 0.805 & 0.369 \\
Inter-Item Correlations & 0.367 & 0.450 \\
\hline
\end{tabular}

Table 3 KMO and Bartlett's Test for Railways sector

\begin{tabular}{|c|c|c|}
\hline \multicolumn{2}{|c|}{ Kaiser-Meyer-Olkin Measure of Sampling Adequacy } & \multirow{2}{*}{$\begin{array}{c}0.903 \\
3.0013\end{array}$} \\
\hline & Approx. Chi-Square & \\
\hline Bartlett's Test of Sphericity & Significant value ( 2 tailed tests). & 0.000 \\
\hline
\end{tabular}




\section{Results}

Table 4: Descriptive statistics of RAILQUAL instrument:

\begin{tabular}{rll}
\hline$\#$ & \multicolumn{1}{c}{ Items in the RAILQUAL } & $\mathbf{\Omega}$ Mean \\
\hline 1. & Staffs of the railway service sector have the ability in solving the & 6.45 \\
& problem of passengers & 6.46 \\
2. & Performance of service correctly & 6.46 \\
3. & Timely provision of service & 6.37 \\
4. & Accuracy in record keeping & 6.28 \\
5. & Accuracy in timing of trains & 6.36 \\
6. & Clarity of announcements in stations & 6.22 \\
7. & Courtesy shown by staffs & 6.29 \\
8. & Ease of communication with the staffs of railways & 6.32 \\
9. & Making customers feel safe during their travel stations & 6.31 \\
10. & Trust towards the staffs & 6.42 \\
11. & Knowledgeable staffs in answering the passengers & 6.28 \\
12 & Special care in dealing with passengers & 6.37 \\
13. & Favorable attitude towards passengers & 6.39 \\
14. & Having the customers best interest at heart & 6.37 \\
15. & Convenient business hours in stations & 6.33 \\
16. & Paying individual attention to all types of passengers & 6.39 \\
17. & Understanding the needs of the customer & 6.34 \\
18. & Infrastructure facilities at stations & 6.38 \\
19. & Infrastructure facilities at Trains & 6.31 \\
20. & Availability of equipments at stations & 6.36 \\
21. & Appearance of staff & 6.28 \\
22. & Promptness in satisfying the requests & 6.38 \\
23. & Staffs sincerity in service & 6.39 \\
24. & Prompt service to passengers & 6.52 \\
25. & Willingness to help the passengers & 6.55 \\
26. & Availability of staffs to respond the passengers & \\
\hline & &
\end{tabular}

The table 4 shows descriptive statistics of RAILQUAL instrument with average mean value. All the 26 items of RAILQUAL are positively accepted by the passengers towards service provider. It reveals that, reliability and responsiveness are the key dimensions which should be focused by the service provider. The overall opinion towards service provider in Ernakulum and Trivandrum districts are satisfied by the passengers.

Table 5: Factors to be consider for choosing service provider

\begin{tabular}{lcccccccc}
\hline \multicolumn{1}{c}{ Factors } & \multicolumn{9}{c}{ Rank preference by respondents } & Mean & Rank \\
& $\mathbf{1}$ & $\mathbf{2}$ & $\mathbf{3}$ & $\mathbf{4}$ & $\mathbf{5}$ & $\mathbf{6}$ & (weight) & \\
\hline Service Quality & 15 & 29 & 29 & 25 & 34 & 17 & 24.33 & 3 \\
Ticket availability & 20 & 21 & 12 & 45 & 30 & 21 & 23.29 & 4 \\
Comfort & 59 & 27 & 28 & 13 & 10 & 12 & 32 & 1 \\
Punctuality & 16 & 23 & 26 & 19 & 31 & 34 & 22.29 & 5 \\
Low charges in & 31 & 37 & 32 & 22 & 21 & 6 & 29.20 & 2 \\
tariff & & & & & & & & \\
More security & 4 & 17 & 22 & 25 & 23 & 58 & 17.90 & 6 \\
\hline
\end{tabular}


The above table 5, it reveals that passengers are asked to rank the factors which they are considered to be an important for choosing this service provider. They will rank from one to seven with one being the most influential factor for selecting the service provider and six being the least influential factor. The passengers giving first rank for comfort with a weighted mean of 32. Closely in second rank is low charges in tariff with having a weighted mean of 29.1 and remaining values of factors are shown in the above table. Passenger consider security as the least important factor for choosing the service provider.

Table 6: Service gap difference between perception and expectation level passengers

\begin{tabular}{|c|c|c|c|c|}
\hline $\mathrm{S} / \mathrm{N}$ & Items of RAILQUAL & Perception & Expectation & Service \\
\hline 1. & Staffs of the railway service sector have the ability in & 4.48 & 6.45 & -1.97 \\
\hline 2. & Performance of service correctly & 4.54 & 6.46 & -1.92 \\
\hline 3. & Timely provision of service & 4.50 & 6.46 & -1.96 \\
\hline 4. & Accuracy in record keeping & 4.86 & 6.34 & -1.48 \\
\hline 5. & Accuracy in timing of trains & 4.28 & 6.28 & -2 \\
\hline 6. & Clarity of announcements & 5.10 & 6.36 & -1.26 \\
\hline 7. & Courtesy shown by staff & 4.34 & 6.22 & -1.88 \\
\hline 8. & Ease of communication with the staffs of railways. & 4.68 & 6.29 & -1.61 \\
\hline 9. & Making customers feel safe during the travel. & 4.58 & 6.32 & -1.74 \\
\hline 10. & Trust towards the staff. & 4.54 & 6.30 & -1.76 \\
\hline 11. & Knowledgeable staffs in answering the passengers & 4.73 & 6.42 & -1.69 \\
\hline 12. & Special care in dealing with passengers & 4.47 & 6.28 & -1.81 \\
\hline 13. & Favorable attitude towards passengers & 4.56 & 6.37 & -1.81 \\
\hline 14. & Having the customer's best interest at heart & 4.48 & 6.39 & -1.91 \\
\hline 15. & Convenient business hour & 4.58 & 6.37 & -1.79 \\
\hline 16. & Paying individual attention to all types of passengers & 4.26 & 6.33 & -2.07 \\
\hline 17. & Understand the needs of the customer. & 4.36 & 6.39 & -2.03 \\
\hline 18. & Infrastructure facilities at stations & 4.48 & 6.34 & -1.86 \\
\hline 19. & Infrastructure facilities at trains & 4.51 & 6.38 & -1.87 \\
\hline 20. & Availability of equipments at stations & 4.36 & 6.30 & -1.94 \\
\hline 21. & Appearance of staff & 4.29 & 6.36 & -2.07 \\
\hline 22. & Promptness in satisfying the requests & 4.36 & 6.27 & -1.91 \\
\hline 23. & Staffs sincerity in service & 4.34 & 6.38 & -2.04 \\
\hline 24. & Prompt service to passengers. & 4.85 & 6.38 & -1.53 \\
\hline 25. & Willingness to help the passengers & 4.66 & 6.51 & -1.85 \\
\hline 26. & Availability of staffs to respond the passengers & 4.58 & 6.55 & -1.97 \\
\hline
\end{tabular}

From the above table 6, it illustrate the Overall RAILQUAL score of railways sector which result the average perception score minus average expectation score that is derived from the 26 paired statements. Using a paired t-test, it indicates a statistically significant difference on the 26 statements which are examined and it is concluded that the hypothesis $\mathrm{H}_{2}$ is rejected. The alternative hypothesis is accepted. So there is an evidence to indicate that customer's perception is lower than expectation of the service offered by the Railways sector.

Table 7: Importance of SQ dimensions in Railways sector

\begin{tabular}{lcc}
\hline Service Quality Dimension & Mean Importance (weights) & Rank \\
\hline Tangibility & 0.22 & 1 \\
Reliability & 0.197 & 3 \\
Responsiveness & 0.199 & 2 \\
Assurance & 0.192 & 5 \\
Empathy & 0.194 & 4 \\
\hline
\end{tabular}

The mean weight represents the extent of importance given by the passengers is depicted in table 7 . The weighted RAILQUAL score is average score that takes into consideration that the weight is assigned by the respondents in each of SQ dimensions. The respondents of railways sector rated "tangibility" as the most important dimension whereas "assurance" as the least important dimension. 
Table 8: Average SQ Gap in Railways Sector

\begin{tabular}{lccccc}
\hline $\begin{array}{l}\text { Factors } \\
\text { Service Quality }\end{array}$ & No of Items & $\begin{array}{c}\text { Perception } \\
\text { Mean }\end{array}$ & $\begin{array}{c}\text { Expectation } \\
\text { Mean }\end{array}$ & $\begin{array}{c}\text { Service Quality } \\
\text { Gap (P-E) }\end{array}$ & $\begin{array}{c}\text { Priority } \\
\text { Rank }\end{array}$ \\
\hline Reliability & 6 & 4.62 & 6.39 & -1.77 & 2 \\
Empathy & 6 & 4.45 & 6.35 & -1.90 & 4 \\
Assurance & 5 & 4.61 & 6.31 & -1.70 & 1 \\
Responsiveness & 5 & 4.56 & 6.42 & -1.86 & 3 \\
Tangibility & 4 & 4.41 & 6.35 & -1.94 & 5 \\
\hline
\end{tabular}

The unweighted RAILQUAL score is the average perception minus average expectation score of the five SQ dimensions of railways is shown in the table 8. By applying the gap analysis, it shows that lowest service gap is occurred in "assurance" and "reliability" dimension and little bigger service gap in occurred in the "tangibility" dimension.

Table 9: Comparison of service quality gap and importance of SQD dimensions

\begin{tabular}{lcc}
\hline Factors of SQ & \multicolumn{2}{c}{ Priority rank by passengers } \\
\cline { 2 - 3 } & Service Gap & Importance \\
\hline Reliability & 2 & 3 \\
Empathy & 4 & 4 \\
Assurance & 1 & 5 \\
Responsiveness & 3 & 2 \\
Tangibility & 5 & 1 \\
\hline
\end{tabular}

The above summary table 9 shows, comparison difference between service quality gap and importance weights rated by the passengers. It concludes that when considering the tangibility dimension will be preferred as the most important one by passengers and subsequently service gap will be very high when compared with other SQ dimensions. Responsiveness dimension is rated second by passengers in giving importance but the service gap is bigger and it ranks third. Assurance dimension has a litter service quality gap and subsequently customers given least importance which ranks fifth.

\section{Predictor of SQ Dimensions on overall service quality of Passengers}

$\mathrm{H}_{2}$ : There is an absence of significant evidence that overall service quality will have a significant impact on individual service quality dimensions of railways.

$\mathrm{H}_{\mathrm{A}}$ : There is significant evidence that overall service quality will have a significant impact on individual service quality dimensions of railways.

The multiple regression is applied to analyze individual service quality dimensions (RATER) as independent variables against a separate measure of Overall Service quality of railways as dependent variable. The independent variables are reliability $\left(\mathrm{X}_{1}\right)$ assurance $\left(\mathrm{X}_{2}\right)$ empathy $\left(\mathrm{X}_{3}\right)$ tangibility $\left(\mathrm{X}_{4}\right)$ responsiveness and $\left(\mathrm{X}_{5}\right)$ and the dependent variable is Overall Service Quality.

Table 10: ANOVA Table for Model Fit

\begin{tabular}{lccccc}
\hline & Sum of Squares & df & Mean Square & F & Sig. \\
\hline Regression & 57.272 & 5 & 11.454 & 14.192 & $.000^{\mathrm{a}}$ \\
Residual & 115.413 & 143 & 0.807 & & \\
\hline
\end{tabular}

The above table 10 tests acceptability of model from a statistical perspective. The ANOVA table shows FRatio for the regression model which indicates statistical significance of the Overall regression model. The F-ratio is result of comparing amount of explained variance to unexplained variance. The F-value is the mean square regression divided by the mean square residual, yielding $\mathrm{F}=14.192$. The $\mathrm{p}$-value associated with this $F$ value is very small $(0.000)$. The significance value of the F-Statistic is greater than 0.05 . In this table the significance variable is less than 0.05 so that the group of variables tangibility, reliability, responsiveness, assurance and empathy (a) can be used to reliably predict Overall Service quality (the dependent variable). 
The relationship between the dependent variable (Overall Service quality) and individual service quality dimensions as independent variables of Railways sector is positive (multiple $\mathrm{R}=0.576$ ). Multiple $\mathrm{R}$ is the correlation coefficient for the simple regression . $R$ - $R$ is the square root of R-Squared and is the correlation between the observed and predicted values of dependent variable. The strength of correlation coefficient is 0.576 . There is a strong positive strength of correlation between the observed variable $\mathrm{X}_{1}$, $\mathrm{X}_{2}, \mathrm{X}_{3}, \mathrm{X}_{4}$ and $\mathrm{X}_{5}$ and predicted values of dependent variable $(\mathrm{Y})$. The adjusted $\mathrm{R}$-square shows percentage of variation in one variable that is accounted by another variable. $R$ square $\left(R^{2}\right)$ is the correlation coefficient squared; also it is referred as the coefficient of determination. The adjusted R-square attempts to yield a honest value to estimate the R-squared for the population and the value is 0.308 .

Regression coefficient for impact of overall Service Quality of railways on individual RATER dimensions: Table 11 shows regression coefficient for independent variables of Railways sector. These are the values for regression equation for predicting dependent variable, Overall Service quality of Railways ( $Y$ ) from the independent variable(s) of RATER dimensions. The t-test examines the question of whether the regression coefficient is different from zero to be statically significant or not. In this step, five independent variables are used to calculate the regression equation for the dependent variable.

The Below table shows the two significant coefficients for railways sector are Responsiveness and Empathy and three non-significant coefficients are tangibility, assurance and reliability dimension. Since the non-significances exceed 0.05 indicating that these variables do not contribute much to the model. It also shows that the relative importance of significant predictors is determined by looking at the standardized coefficient. Responsiveness dimension has the highest standardized coefficient with the lowest significance $(\mathrm{p}<=0.05)$ which means that "Responsiveness" is the main predictor for overall service quality of railways. The predicted value (regression equation) is, $Y_{1}$ predicted (overall service quality of Railways sector) $=2.194+.908^{*}$ Reliability $+2.769^{*}$ Assurance $+5.440 *$ Empathy + $2.461 *$ Tangibility $+6.787 *$ Responsiveness.

By applying descriptive statistics, demographic profile of passengers, majority of passengers $38.3 \%$ are students, $19.5 \%$ passengers are belongs to Own business category, professionals are $8.7 \%$ and remaining passengers are Academicians(7.4\%), and clerk (4.7\%).The income wise classification majority of respondents are lies between Rs $10001-15000$ having $25.5 \%$ and $14.8 \%$ percentage of passengers are between income level of Rs 5000-10000. The gender wise classification seventy are male respondents and remaining seventy nine are female respondents The age wise classification, majority of respondents $(47.7 \%)$ belongs to the age group of 20 to $29,20.1 \%$ respondents belongs to the age group of 30 to 39 and the remaining percentage of respondents belongs to the age group of 40 to 59

In Trivandrum district out of 77 samples, most of the respondents are using Vanchinadu Express, second preference is Chennai mail, Kerala Express and Bangalore Express, Mumbai Express. Nizamudeen Express and Madurai Passenger service providers are considered as the least used service providers by Trivandrum passengers. In Ernakulam district out of 73 samples, 28 passengers are using Kerala Express, next to it Lokmanya Express and the least preference to Kollam Passenger and Intercity Express

Table 11: Regression coefficients for model

\begin{tabular}{|c|c|c|c|c|c|}
\hline & \multicolumn{2}{|c|}{ Unstandardized Coefficients } & \multirow{2}{*}{$\begin{array}{c}\text { Standardized Coefficients } \\
\text { Beta } \\
\end{array}$} & \multirow{2}{*}{ t-value } & \multirow{2}{*}{ p-value } \\
\hline & B & Std. Error & & & \\
\hline (Constant) & 2.194 & 0.376 & & 5.838 & 0.000 \\
\hline Reliability & 0.908 & 2.526 & 0.036 & 0.360 & 0.720 \\
\hline Assurance & 2.769 & 3.484 & 0.089 & 0.795 & 0.428 \\
\hline Empathy & 5.440 & 2.621 & 0.231 & 2.075 & 0.040 \\
\hline Tangibility & 2.461 & 3.273 & 0.072 & 0.752 & 0.453 \\
\hline Responsiveness & 6.787 & 3.341 & 0.233 & 2.031 & 0.044 \\
\hline
\end{tabular}

By applying the regression analysis the orders of significance for predictor dimensions of Overall Service quality of railways sector are Empathy and Responsiveness. The predicted value (regression equation) is $\mathrm{Y}_{1}$ predicted (overall service quality of Railways sector) $=2.194+.908 *$ Reliability $+2.769^{*}$ Assurance+ 
$5.440 *$ Empathy $+2.461 *$ Tangibility $+6.787 *$ Responsiveness. By applying reliability test, it is revealed that the five $S Q$ dimensions for the total scale have resulted in good internal consistency, which is evidenced by Alpha method. All the five dimensions of RAILQUAL instrument has a coefficient alpha value of 0.934 in perception scale and 0.951 in expectation scale

By applying gap analysis the comparison difference between service quality gap and importance weights by passengers is found. It concludes that when considering the tangibility dimension will be preferred as the most important one by passengers and subsequently service gap will be very high when compared with other SQ dimensions. Responsiveness dimension is rated second by passengers in giving importance but the service gap is bigger and it ranks third. Assurance dimension has a litter service quality gap and subsequently customers given least importance which ranks fifth. Empathy dimension service gap is bigger with reliability dimension but the passengers are not given importance which ranks fourth. By applying factor analysis, it is found that all the 26 items of RAILQUAL are positively accepted by the passengers towards service provider. The reliability and responsiveness dimension are the key dimensions, should be focused by the service provider

By applying the regression analysis orders of significance for predictor dimensions of Overall Satisfaction of railways sector are Empathy and reliability. The predicted value (regression equation) is $Y_{1}$ predicted (Overall satisfaction of Railways sector) $=1.914+5.450 *$ Reliability $+3.867^{*}$ Assurance $+5.121 *$ Empathy + $0.523^{*}$ Tangibility $+3.460 *$ Responsiveness. By ranking method, the passengers giving first rank one for comfort, closely second rank is Low charges of tariff. Passenger considers more security as the least important reason for choosing the service provider. By using ranking method, the Passengers giving preference to Sleeper Class as the rank one, closely second rank is third A.C, second A.C and first class holds the least rank by the passenger's preferences.

\section{Conclusion}

The empirical investigation study is able to accomplish research objectives, by thoroughly analyzing and identifying competitive position of railways strengths and weaknesses among the passengers. It is concluded that industry could initiate various steps based on the recommendations given in the empirical research. Getting periodical feedback from the customers in their respective train's at least six months once. The infrastructure facility in both trains and railway stations has to be improved. The second seating class will be improved towards the customers' expectation. The industry has to adopt recommendations, if not all, can further improve its performance and occupy a leading position among the customer minds in future years to come.

\section{References}

Geetika, S. \& Nandan S. (2010).Determinants of Customer Satisfaction on Service Quality: A Study of Railway Platforms in India. Journal of Public Transportation, 13(1), 97-113.

Maruvada D, P. \& Bellamkonda R. S. (2010). Analyzing the Passenger Service Quality of the Indian Railways using Railqual: Examining the Applicability of Fuzzy Logic, International Journal of Innovation, Management and Technology, 1(5), 478-182.

Parasuraman, A. Zeithamal, V. A. \& Berry, L. L. (1985). SERVQUAL: A Multiple item scale for measuring customer perception of service quality. Journal of Retailing, 64(1), 12-40.

Rahaman, R. K. and Rahaman, Md. A. (2010). Service quality attributes affecting the satisfaction of railway passengers of selective route in southwestern part of Bangladesh, 1(5), 478-482.

Rust, R. T \& Oliver, R. L. (1994). Service quality: Insights and managerial implications from the frontier. In Rust RT, Oliver RL, ed., Service Quality: New Directions in Theory and Practice London: Sage, 119.

Vanniarajan, T. \& Stephen, A. (2008). Railqual and passenger satisfaction an empirical study in Southern railway. Asia Pacific Business Review, 4(1), 12-20. 